Jurnal Geocelebes Vol. 1 No. 1, April 2017, Hal 17 - 22

\title{
IDENTIFIKASI POLA SEBARAN INTRUSI BATUAN BAWAH PERMUKAAN MENGGUNAKAN METODE GEOMAGNET DI SUNGAI JENELATA KABUPATEN GOWA
}

\author{
Nur Hidayat Nurdin ${ }^{1 *}$, Muh. Altin Massinai ${ }^{2}$, Sabrianto Aswad $^{2}$ \\ ${ }^{1}$ PT HADE GEOSAINS, Makassar \\ ${ }^{2}$ Program Studi Geofisika, FMIPA Universitas Hasanuddin, Makassar \\ *Penulis koresponden. Alamat email: yaboblack8@gmail.com
}

\begin{abstract}
Abstrak
Penelitian ini dilakukan di Sungai Jenelata, Kabupaten Gowa, Sulawesi Selatan mengunakan metode geomagnet. Tujuan dari penelitian ini yaitu mengidentifikasi struktur geologi bawah permukaan pada daerah penelitian. Jumlah titik pengukuran sebanyak 248 dengan area seluas $70 \times 300$ meter. Akuisisi data dilakukan dengan menggunakan satu alat magnetometer. Sementara pengolahan data menggunakan koreksi harian dan koreksi IGRF serta filter upward continuation. Pemodelan dilakukan dengan metode forward modeling dengan menggunakan perangkat lunak Mag2DC. Medan magnetik total berkisar antara 42.456 sampai 43.111,6 nT. Berdasarkan interpretasi kualitatif pada kontur anomali magnetik lokal didapatkan variasi nilai anomali antara -320 sampai $240 \mathrm{nT}$. Sedangkan interpretasi kuantitatif menunjukkan adanya batuan basalt dengan nilai suseptibilitas $-0,02 \times 10^{-3}$ sampai $0,02 \times 10^{-3} \mathrm{SI}$, yang menerobos batuan pyroclastic dengan nilai suseptibilitas $-0,001 \times 10^{-3}$ hingga $-0,01 \times 10^{-3}$ SI dalam dalam bentuk $d y k e$.
\end{abstract}

Kata Kunci: Geomagnet, dyke, Suseptibilitas, Sungai Jenelata.

\begin{abstract}
This research has been conducted using geomagnetic method at Jenelata River, Gowa regency, South Sulawesi. The purpose of this study is to identify subsurface geological structure of the study area. The number of measurement points as much as 248 points with area $70 \times 300$ meters. The process of data acquisition using a magnetometer. Data processing was carried out with the diurnal correction and IGRF correction and using filter upward continuation. Modelling conducted using forward modeling using the software Mag2DC. The total magnetic field ranges from 42,456 to 43,111.6 nT. Based on a qualitative interpretation obtain local magnetic anomaly contour variations values between -320 to $240 \mathrm{nT}$. While the quantitative interpretation indicates basalt rocks with susceptibility values $-0,02 \times 10^{-3}$ to $0,02 \times 10^{-3} \mathrm{SI}$, which breached pyroclastic rocks with susceptibility values $-0,001 \times 10^{-3}$ to $-0,01 \times 10^{-3} \mathrm{SI}$, in the form of dyke.
\end{abstract}

Keywords: Geomagnetic, dyke, Susceptibility, Jenelata River. 


\section{Pendahuluan}

\section{Geologi Regional}

Pada peta geologi sistematik Indonesia skala 1:250.000, daerah penelitian termasuk dalam Peta Geologi Lembar Ujungpandang, Benteng, dan Sinjai. Batuan tertua yang tersingkap adalah batuan malihan yang berumur kapur. Batuan malihan ini ditindih secara tidak selaras oleh formasi Marada yang merupakan sedimen flysch dan berumur kapur atas. Batuan gunung api terpropilit-kan yang berumur Paleogen menindih secara tidak selaras sedimen flysch tersebut (Sukamto, 1982).

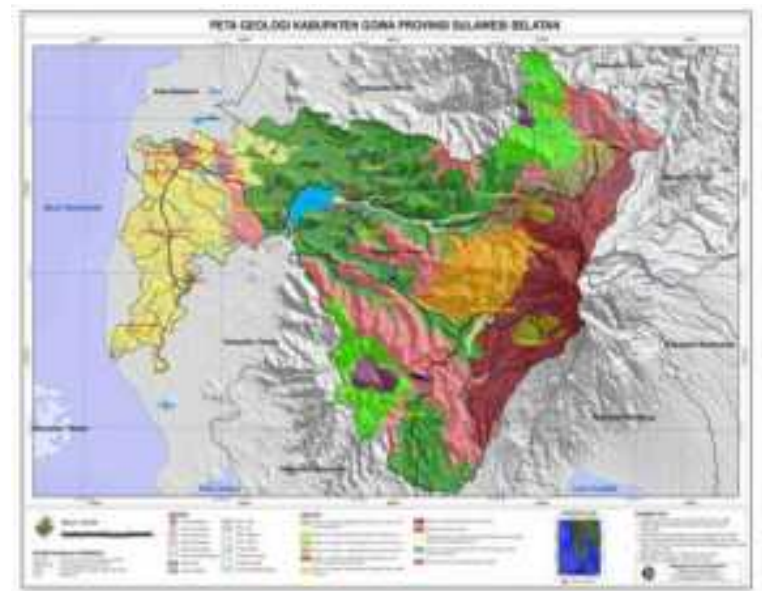

Gambar 1 peta geologi kabupaten gowa

\section{Bentang alam Gunungapi Sapaya}

Bentang alam Gunungapi Sapaya memperlihatkan relief kasar (perbukitan pegunungan) yang disusun oleh breksi aliran piroklastik (satuan breksi) dan tuf (satuan tuf). Bentang alam ini membentuk lengkungan berdiameter lebih besar dari 2 $\mathrm{km}$ yang diduga sebagai kaldera. Adanya kaldera ini menunjukkan gunungapi ini pernah mengalami erupsi cukup dahsyat. Bentuk bentang alamnya sekarang ini tidak kerucut lagi, diduga disebabkan oleh suatu letusan dan kemudian diikuti oleh proses erosi cukup intensif (Sidarto, 2009).

\section{Metode Geomagnet}

Gaya Magnet yang ditumbulkan oleh dua kutub yang terpisah dengan jarak $r$ dan muatannya masing-masing $\mathrm{m}_{1}$ dan $\mathrm{m}_{2}$ diberikan oleh :

$$
F=\frac{1}{\mu} \frac{m_{1} m_{2}}{t^{2}} \hat{r}
$$

Dimana :

$=$ permeabilitas magnetik yang menunjukkan sifat suatu medium

$\mathrm{F}=$ gaya magnetik

$\hat{r}=$ vektor satuan berarah dari $\mathrm{m}_{1}$ ke $\mathrm{m}_{2}$

$\mathrm{m}=$ muatan kutub magnetik

$\mathrm{r}=\mathrm{jarak}$

kuat medan magnet dapat dinyatakan sebagai :

$H=\frac{1}{\mu} \frac{m_{1}}{t^{2}} \hat{r}$

$\mathrm{m}_{1}$ dianggap sebagai kutub intrumen pengukuran yang digunakan.

$\mathrm{m}_{2}=$ kutub magnet yang diukur.

Kerapatan arus magnet yaitu jumlah arus dalam satu satuan daerah yang juga disebut induksi magnet dinyatakan dengan

$B=\mu H$

Medan magnet yang terukur oleh alat magnetometer adalah medan magnet induksi, termasuk efek magnetisasi yang diberikan oleh persamaan (Darwis, 2001) :

$B=\mu_{0}(H+M)$

\section{Dimana :}

$\mathrm{M}=$ momen dipol magnetik dalam satuan skalar

$0=$ permeabilitas dalam ruang vakum $(0$ $=1$ (Telford, dkk, 1990)).

Dalam kemagnetan dikenal suatu sifat dasar yaitu kerentanan magnet (suseptibilitas magnet) yang disimbolkan $\kappa$. dalam ruang hampa $\kappa=0$. Intensitas magnetisasinya dapat ditulis sebagai berikut (Untung, 2001) : 
$M=k H$

Dengan demikian, jika dihubungkan dengan persamaan (2.5), persamaannya menjadi :

$B=\mu_{0}(1+k) \cdot H$

\section{Forward Modeling}

Forward modeling disebut juga permodelan tidak langsung. Permodelan ini betujuan untuk memberi gambaran secara matematik geometri benda penyebab anomali. Pada umumnya berupa suatu poligon yaitu suatu benda dengn sudut banyak. Pengukuran geomagnet mengukur medan magnet total, yaitu besaran medan magnet bumi ditambah dengan medan yang beranomali. Kemagnetan imbasan selalu sejajar dengan medan magnet bumi.

\section{Upward Continuation}

Kontinuitas ke atas dilakukan dengan mentransformasikan medan potensial yang diukur di permukaan tertentu ke medan potensial pada permukaan lainnya yang jauh dari sumber. Tranformasi ini memperlemah anomali-anomali sebagai fungsi panjang gelombang.

\section{Metode Penelitian}

Penelitian ini dilakukan di sungai Jenelata, perbatasan antara Desa Tanakaraeng dengan Desa Moncongloe Kecamatan Manuju Kabupaten Gowa. Luas daerah penelitian berukuran 70 x $300 \mathrm{~m}$. Daerah ini dibagi dalam 8 lintasan dengan jarak antar titik ukur $10 \mathrm{~m}$.

Penelitian menggunakan satu alat proton magnetometer dengan metode looping.

Prosedur penelitian meliputi tahap akuisisi, pengolahan data dan intepretasi. Pengolahan data dilakukan dengan koreksi harian dan koreksi IGRF serta menggunakan filter upward continuation. Pemodelan dilakukan dengan metode forward modeling dengan menggunakan peragkat lunak Mag2DC. Interpretasi data dilakukan secara kuantitatif dan kualitatif.

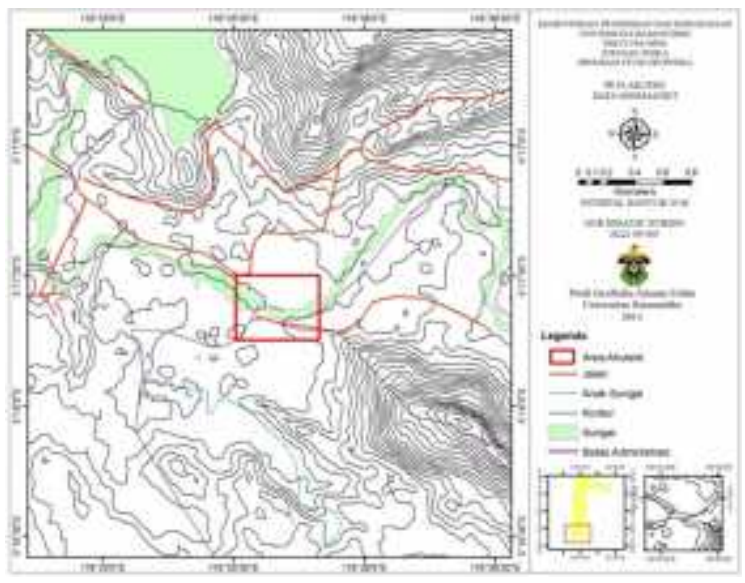

Gambar 2 lokasi penelitian

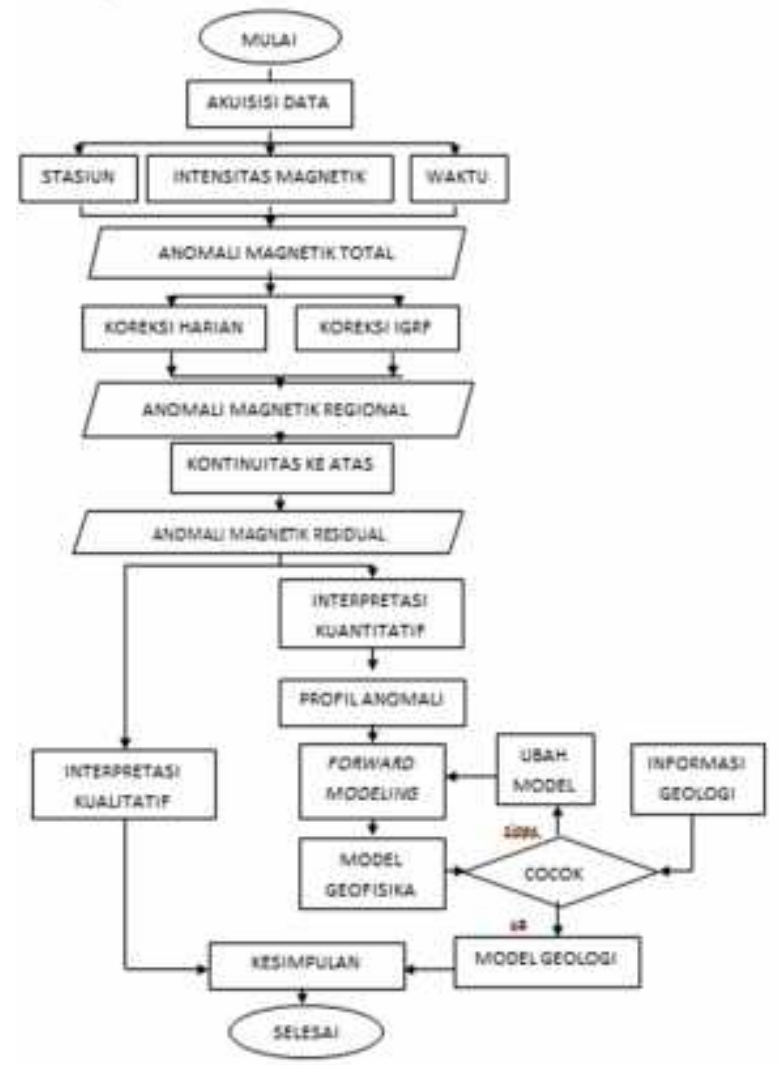

Gambar 3 Bagan Alir Penelitian 


\section{Hasil dan Pembahasan}

Pengukuran medan magnet total yang telah dilakukan di lokasi penelitian diperoleh data intensitas magnetik total berkisar antara 42.456 sampai 43.111,6 nT.

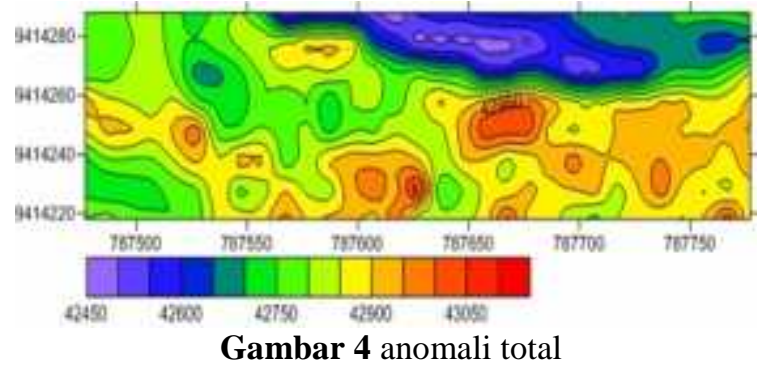

Setelah dilakukan koreksi harian dan koreksi IGRF, intensitas anomali magnetik regional berkisar -640 sampai -180 nT.

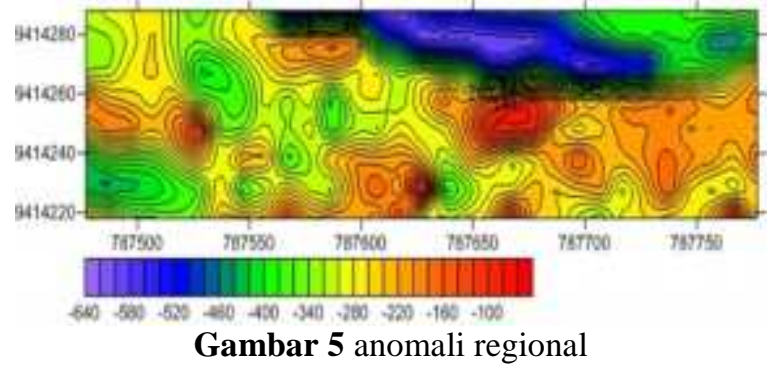

Hasil dari filter upward continuitas menunjukkan anomali lokal daerah penelitian.

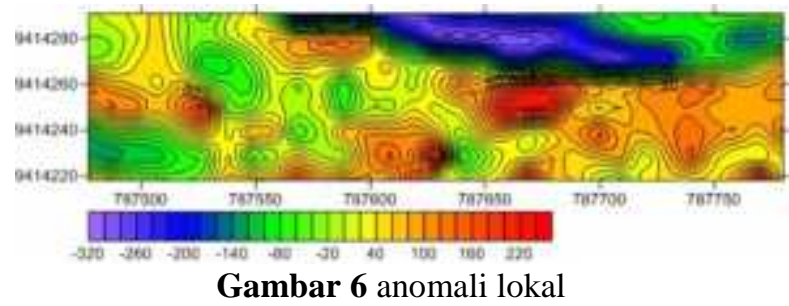

\section{Interpretasi Kualitatif}

Interpretasi kualitatif dilakukan dengan menganalisa kontur anomali medan magnetik lokal. Berdasarkan pola kontur anomali dapat dilihat posisi dari dyke yang menjadi sumber anomali. Adapun perbedaan anomali yang mencolok pada bagian kanan atas peta kontur anomali residual timbul akibat perbedaan ketinggian dan jumlah sedimen yang menutupi batuan dasar (sumber anomali) yang tersingkap di dasar sungai. Perbedaan ketinggian antara tepi sungai dan dasar sungai bervariatif antara 15 meter di sisi selatan sungai dan 2-11 meter di sisi bagian utara sungai.

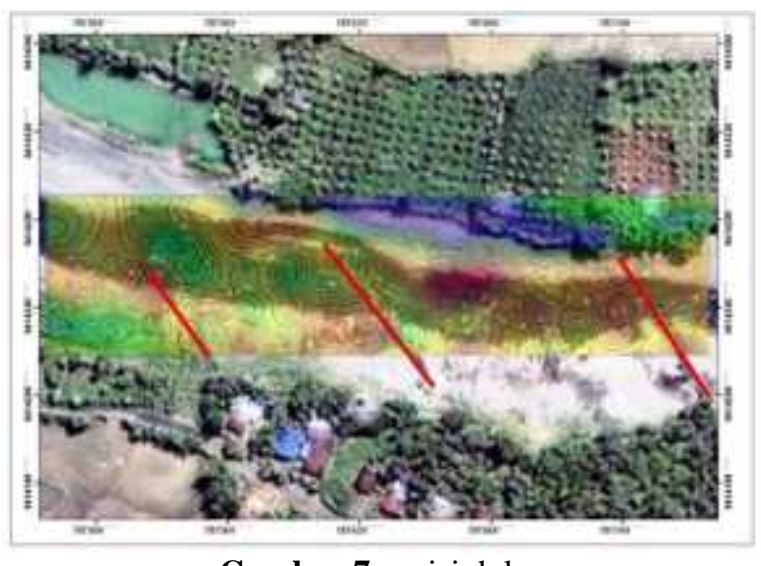

Gambar 7 posisi dyke

\section{Interpretasi Kuantitatif}

Interpretasi kuantitatif dilakukan berdasarkan profil batuan hasil forward modeling dari mag2dc dan informasi geologi dari lokasi penelitian.

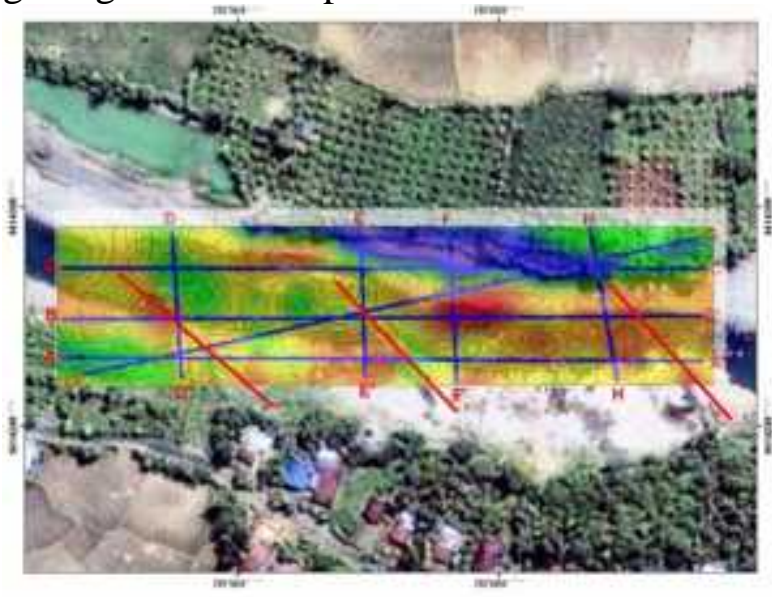

Gambar 8 sayatan pada kontur anomali 


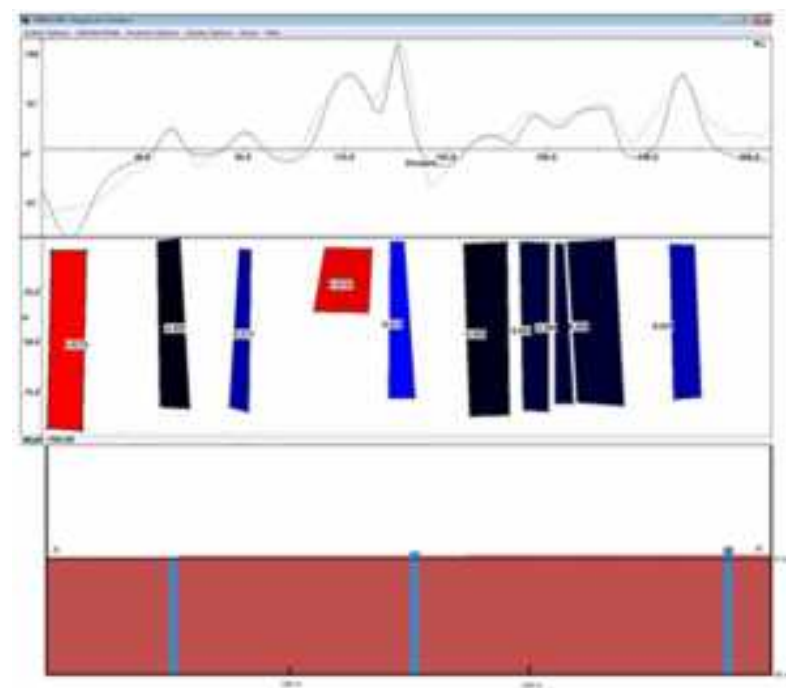

Gambar 9 sayatan AA'

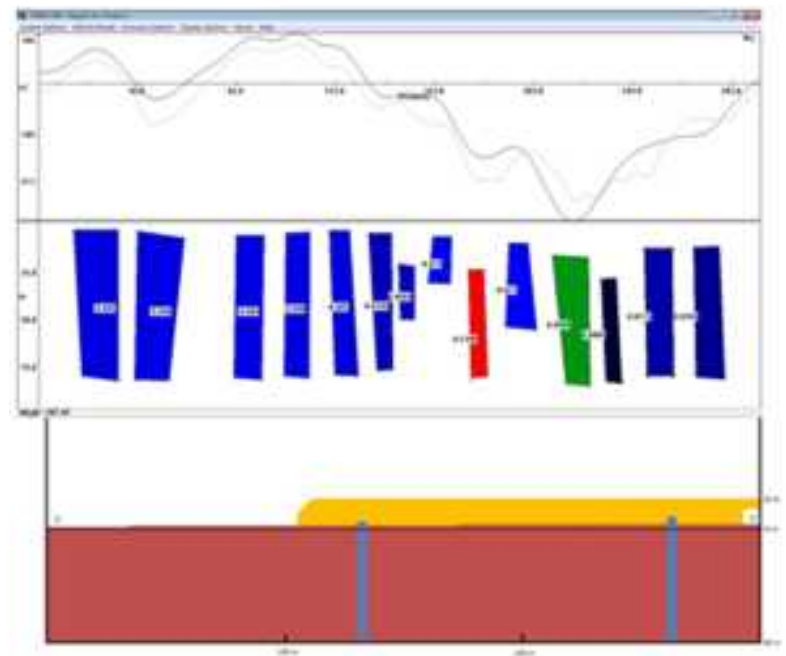

Gambar 10 sayatn CC'

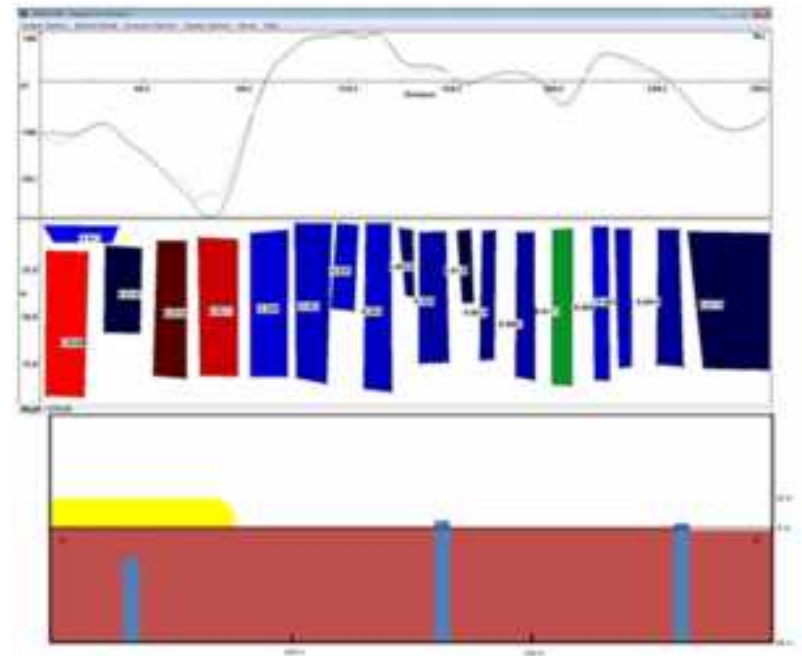

Gambar 11 sayatan GG'
Berdasarkan nilai suseptibilitas yang diperoleh dari forward modeling dapat diketahui posisi batuan bawah permukaan. Dengan menggabungkan hasil dari model dan informasi geologi yang diperoleh dari lokasi penelitian, diketahui terdapat 3 batuan utama yang memberikan pengaruh medan magnet pada lokaasi penelitian, yakni basal dengan nilai suseptibilitas $-0.02 \times 10^{-3}$ sampai $0.02 \times 10^{-3} S$, pyroclastic dengan nilai suseptibilitas $-0.001 \times 10^{-3}$ hingga $-0.01 \times 10^{-3} S$, dan shale/aluvium dengan nilai suseptibiltas $0.01 \times 10^{-3} \mathrm{~S}$.

\section{Kesimpulan}

Berdasarkan hasil penelitian dan hasil interpretasi struktur bawah permukaaan di lokasi peneitian dapat disimpulkan bahwa:

1. Nilai suseptibilitas batuan di lokasi penelitian $\quad-0.02 \times 10^{-3}$ sampai $0.02 \times 10^{-3} \mathrm{SI}$ untuk batuan basal, $-0.001 \times 10^{-3}$ hingga $\quad-0.01 \times 10^{-3} S I$ untuk batuan pyroclastic, dan $0.01 \times 10^{-3} S$ untuk shale.

2. Batuan dasar yang tersingkap di dasar sungai berupa dyke basal yang menerobos batuan pyroclastic.

3. Perbedaan anomali yang mencolok pada daerah penelitian disebabkan oleh adanya dyke yang tersingkap di dasar sungai, tutupan sedimen di atas batuan dasar yang tersingkap dan perbedaan ketinggian antara dasar sungai dan tepi sungai yang berupa tebing.

\section{Saran}

1. Untuk pendugaan kondisi geologi bawah permukaan yang lebih detail dapat kombinasikan dengan metode geofisika yang lain, seperti geolistrik, seismik, dan GPR 
2. Untuk memudahlan pengukuran sebaiknya mengunkan 2 alat magnetometer.

\section{Daftar Pustaka}

Sidarto, dan U. Hartono. 2009.Identifikasi Gunungapi Purba Di Daerah Sapaya, Sulawesi Selatan Pada Data Inderaan Jauh. Pusat Survei Geologi : Bandung.

Sukamto, R.. dan Supriatna. 1982. Geologi Lembar Ujungpandang, Benteng, dan Sinjai, Sulawesi Selatan.Pusat Penelitian dan Pengembangan Geologi : Bandung.

Telford, W. M., dkk. 1990. Applied Geophysics Second Edition. Cambridge University. New York, USA.

Untung, M.. 2001. Dasar-dasar Magnet dan Gaya Berat Serta Beberapa Penerapannya. HAGI. Jakarta. 